\title{
El reto educativo: análisis y propuestas ${ }^{1}$
}

\author{
Pierpaolo Donati
}

University of Bologna (Italia)

\section{Comprender la emergencia educativa: identificar el problema}

La situación de la educación de las nuevas generaciones, en Italia como en tantos otros países modernizados, ha sido foco de interés de muchos estudios e investigaciones. Sin embargo, me parece que gran parte de la opinión pública no ha captado todavía el sentido más profundo de aquello que resulta una "situación de emergencia".

Desde hace tiempo se habla de "emergencia educativa". ¿ Pero en qué consiste verdaderamente? Es obvio observar que esta expresión indica el hecho de que las nuevas generaciones parecen difusamente preparadas para llevar una vida sensata y satisfactoria, que lo sea para ellas y para otras generaciones. Se subraya el hecho de que entre los jóvenes se difunden comportamientos siempre más incívicos, incompetentes, desviados, violentos, con cotas que rozan la barbarie y lo deshumano (por ejemplo, prender fuego a indigentes de la calle, asaltar en grupo a un compañero para robarle pequeñas cosas, bullying, pertenecer a sectas satánicas, etc.). Más en general, se denuncia el hecho de que las nuevas generaciones viven de modo desorientado, sin metas precisas, sin compromisos serios en términos de preparación profesional o de maduración moral.

Muchos estudios de investigación compiten en poner de relieve la gravedad de la situación. Las estadísticas sobre comportamientos de los menores son alarmantes. Educadores y padres denuncian su impotencia.

Se subraya el hecho de que, antes que la escuela, es la familia quien se encuentra con grandes dificultades respecto al desafío educativo, y en muchos ámbitos ya lo ha perdido. Se demuestra que, tras niños frágiles y desorientados, están padres que han sido poco o nada preparados para afrontar el reto educativo.

1 Publicación original: Donati, P. (2010). La sfida educativa: analisi e proposte. Orientamenti Pedagogici, 57 (4), 581-608. Traducción: Nuria Garro-Gil, Departamento de Teoría y Métodos de Investigación Educativa y Psicológica, Facultad de Educación y Psicología, Universidad de Navarra (España).nggil@unav.es

DOI: 10.5294/edu.2015.18.2.7

Para citar este artículo / To reference this article / Para citar este artigo

Donati, P. (2015). El reto educativo: análisis y propuestas. Educ. Educ., 18 (2), 307-329. DOI: 10.5294/edu.2015.18.2.7 
Todo esto ya era vaticinado en un estudio sociológico de hace algunos años, que traía a la luz la creciente incerteza, precariedad, falta de capacidad y de posibilidad proyectiva de las nuevas generaciones (Donati y Colozzi, 1997). Aquí no es posible examinar los resultados alarmantes de aquella investigación que ha hecho historia en el campo de los estudios sociológicos, porque por primera vez ha definido a los jóvenes "generacionalmente", es decir, como una generación que debe ser generada y que debe a su vez ser capaz de generar. Desde entonces, las tendencias negativas se han agudizado.

Sabemos que los problemas educativos están afectando a los jóvenes a edades siempre más precoces. Algunos documentos europeos, como el informe ESPAD 2009, ${ }^{2}$ revelan que el abuso de psicofármacos (obviamente no prescritos regularmente, sino adquiridos en el mercado clandestino), está asociado a algunos indicadores de comportamiento problemático ya en jóvenes de 15-16 años: el primer indicador es el relativo a un escaso rendimiento escolar, el segundo a una relación difícil con los progenitores.

El hecho es que, en líneas generales, los progenitores aman profundamente a sus hijos y los proveen materialmente, pero no los educan. Algunos no saben educar, otros lo saben (tienen un proyecto formativo), pero no consiguen realizarlo por dificultades de todo tipo. Podemos estimar las proporciones así: cerca de un tercio de los progenitores carece totalmente de formación (estos progenitores no han sido social y culturalmente "generados" y, en consecuencia, no sienten el impulso de generar social y culturalmente a los hijos); otro tercio tiene una

2 El informe ESPAD 2009 (Proyecto Europeo de estudios escolares sobre alcohol y drogas), que muestra los datos relativos a un estudio que ha congregado a cerca de 100.000 estudiantes europeos de 15-16 años, revela que entre los adolescentes europeos el consumo de tabaco disminuye, pero ha aumentado el uso de alcohol y de psicofármacos; se estabilizan, en cambio, el cannabis y la cocaína. Estas "nuevas" formas de abuso revelan la búsqueda de un "rumor" al mismo tiempo eufórico, alegre y anestesiante, que se puede obtener con la asociación de superalcohólicos, psicofármacos y cannabis. cierta formación, pero se siente desorientado; solo un tercio tiene una relativa buena formación y actúa con una cierta posibilidad de éxito en la educación de los hijos. Lo que significa que dos tercios de los progenitores han perdido ya el desafío educativo.

Frente a las elecciones de valor, a las dimensiones proyectivas de la vida, a las construcciones de sentido y de significado, buena parte de los adultos se ha retirado, dejando a los niños y a los adolescentes solos. Así, se ha acentuado posteriormente la brecha generacional, que las nuevas tecnologías enfatizan continuamente: las comunidades de los niños y de los adolescentes, utilizando un nuevo camino para la construcción del saber a través de la tecnología digital, han dado vida a mecanismos autorreferenciales con los que se gobiernan a ellos mismos, indiferentes al mundo lejano y poco fascinante de los adultos. Al contrario, los adultos han adoptado formas de infantilización de su estilo de vida, copiando por ejemplo el dialecto virtual de los sms de sus hijos y permitiéndose transgresiones más propias de un adolescente que de un adulto. En definitiva, el adulto no está ya en situación de ser un individuo reconfortante, que ha madurado una visión del mundo y que la desea transmitir, porque ni a él mismo le ha fascinado. Es el paso de la sociedad que todavía tenía referentes en metanarraciones de tipo religioso o ideales, y también ideológico, a una sociedad denominada "líquida", en la que —en apariencia-caen todas las instituciones y las estructuras socioculturales estables.

Lo que está en juego es justamente la relación educativa, por ambas partes: ¿qué deben hacer los progenitores frente a los hijos que han creado su mundo comunicativo totalmente alejado de las relaciones interpersonales en familia? ¿Qué deben hacer los adolescentes para recuperar el interés de sus padres que se muestran ajenos y desinteresados por las nuevas tecnologías de la comunicación?

A pesar de que los adultos expertos conocerán ya bien el fenómeno del bullying, en Italia los mass 
media lo han descubierto a través de Youtube: un lugar poco frecuentado por el progenitor medio. Los adolescentes han colgado videos cada vez más inquietantes (de los golpes e insultos a un chicho con síndrome de Down, a las agresiones de un grupo a una niña; de las insinuaciones eróticas a una profesora, a las relaciones sexuales consumadas en clase; e incluso, videos sobre destrozos en la escuela, insultos a los profesores, etc.). Síndromes patológicos reservados hasta ahora a profesionales expertos, acaban en Internet y han adquirido así la patente de fenómenos considerados "normales" a los ojos de muchos. Se piensa, por ejemplo, en el drama de las chicas "transparentes", que han colgado en la red sus blogs en los cuales hacen ver su espantosa delgadez (son famosos los sitios pro-ANA, es decir, sitios web que exaltan la anorexia y animan a los jóvenes a unirse a las consiguientes reglas de vida). ${ }^{3}$ Las emergencias sociales de los adolescentes sobre las que los mass media centran la atención se llaman bullying, depresión, hipocondría.

Evidentemente, todo lo señalado no son sino síntomas pero no es la sustancia del problema. Debemos distinguir los síntomas de la crisis educativa, de sus causas más profundas. ¿Dónde están las causas primeras? ¿Dónde está el origen del desafío?

La emergencia educativa no consiste solo en poner de relieve la difusión de las condiciones patológicas, una especie de orden psicológico y relacional, a edades siempre más precoces; tampoco de comportamientos desviados y violentos entre cotas crecientes de jóvenes, sino que consiste también y

3 Un típico ejemplo de decálogo "PRO-ANA" es el siguiente, he aquí los diez mandamientos: 1) si no estás delgada no eres atractiva, 2) estar delgados es más importante que estar sanos, 3) compra vestidos, córtate el pelo, toma laxantes, muere de hambre, hazlo todo para parecer más delgada, 4) no puedes comer sin sentirte culpable, 5) no puedes comer comidas grasas sin castigarte después, 6) debes contar las calorías y reducir la ingesta en consonancia, 7) lo que dice la báscula es lo más importante, 8) perder peso está bien, conservar peso es malo, 9) no estarás nunca demasiado delga$\mathrm{da}, 10)$ estar delgada y no comer son símbolos de verdadera fuerza de voluntad y autocontrol. sobre todo, en que nuestra sociedad (la cultura dominante en las instituciones de socialización) teoriza el hecho de que las instituciones tradicionales de educación no pueden ya educar a las nuevas generaciones.

Se hallan frente a una sociedad que se considera incapaz de formar y orientar a los jóvenes. Esta sociedad permanece estructuralmente inhabilitada para hacerlo. Como luego diré, esta es la representación que nos viene dada por los gurús de la sociología internacional, aquellos que, como Ulrick Beck, Antony Giddens, Scott Lash y otros, teorizan sobre la llegada de la denominada "modernización reflexiva". Un término cuanto menos equívoco, dentro del cual se esconde la legitimación de un modelo de sociedad que renuncia a cualquier forma de educación, dado que la modernización viene a coincidir con la autorrealización individualista y narcisista de los puros individuos "casuales".

En resumen, quisiera sostener aquí que la cuestión de la emergencia educativa no consiste en el hecho de que nos encontremos frente a una sociedad que querría educar, pero fracasa. La cuestión es incluso más grave y radical: la emergencia educativa reside en el hecho de que la imposibilidad para educar se piensa como una condición normal de la sociedad en la que vivimos.

Esta ha resultado inevitable, e incluso deseable y previsible, en tanto que nuestra sociedad se ha concebido como abierta a la máxima variabilidad posible de opciones y de comportamientos, por lo que la misma desviación se ha incorporado como una de tantas posibilidades admisibles, hasta ser progresivamente incluida como comportamiento "normal" con la sola condición de no infringir los mismos derechos de los demás a hacer lo mismo. En esto consiste la verdadera naturaleza de la emergencia educativa.

Los jóvenes "giran en el vacío", no solo por la falta de oportunidades, o por la ausencia de padres 
y de profesores válidos, sino porque la sociedad en la que viven les enseña que no deben tener metas y hacer proyectos dado que serían de todas formas irrealizables. Es ciertamente generoso por parte de muchos padres y profesores intentar proponer modelos válidos de vida, pero el hecho es que los jóvenes los observan sin la confianza de poder realizarlos.

Me parece que nos estamos acercando a ese umbral más allá del cual los problemas educativos podrían volverse dramáticos en el sentido de que las jóvenes generaciones sería abandonadas a sí mismas - deberían cada vez más defenderse solas-en su formación humana, profesional y moral, puesto que las instituciones formativas no consiguen estar a la altura del desafío por el simple hecho de que se entiende que no están preparadas (no legitimadas) para esta tarea. Es otra de las múltiples consecuencias de la separación entre lo humano y lo social típica de nuestra sociedad (Donati, 2009a): lo social se autonomiza respecto de lo humano, y la presión social dice que debe ser así.

Sin embargo, dejando a un lado estas cuestiones, afirmo que la emergencia educativa afecta antes que nadie a los adultos, las generaciones que han bautizado esta sociedad, esa en la que estamos viviendo, y que los niños y las jóvenes generaciones son más las víctimas que los artífices de la actual emergencia educativa.

El malestar de la modernidad se ha manifestado primeramente en términos culturales y psicológicos: se ha puesto en evidencia la desorientación valorativa, el vacío existencial, la pérdida de significados vitales forjados por las tradiciones religiosas, el relativismo cultural, la sustitución de la ética de las virtudes por la ética de las emociones, ${ }^{4}$ etc.

Todo esto tiene que ver con la crisis interna de la modernidad, que viene de atrás, pero que se

4 Véanse los análisis, por ejemplo, de Alasdair Maclntyre (1988) y Charles Taylor (1994) acentúa en el curso del siglo XXI y con el ocaso del modelo de sociedad que se había estabilizado en la segunda posguerra.

Aunque resulte evidente la utilidad de tener un poco de orden y disciplina en las escuelas, como en general en los procesos educativos, la idea de que la emergencia educativa pueda ser afrontada con una estrategia de tipo "disciplinar" está destinada a encontrarse solo con desilusiones. Poner un poco de orden aquí podrá indudablemente ayudar a crear un clima más protector y un mayor sentido de estabilidad y seguridad, pero no podrá educar en el sentido propio del término.

El problema de fondo es el de cómo puede ser posible educar en una sociedad que vive la crisis radical de la modernidad.

Un inciso. Durante más de dos siglos, la religión cristiana ha seguido a la modernidad sobre el terreno de la racionalidad, y todavía continúa haciéndolo. La respaldan grandes pensadores, como Charles Taylor (2009) y Robert Spaemann (2010). Infortunadamente, estos autores, aunque notables, no comprenden que el terreno de la racionalidad, modificado completamente en el curso de la modernidad, no es ya tratado de modo adecuado si se queda en el interior de categorías filosóficas clásicas. Desde mi punto de vista, el camino que se aleja de la vía de una renovación de la razón no puede producir grandes resultados si no se acompaña de una nueva lectura, relacional, de la razón. Se necesita elaborar un concepto de "razón relacional" (Donati, 2008a). Si la teoría y la práctica continúan ignorando esta cuestión, producen efectos no deseados. En particular, se termina por encoger la reserva escatológica y espiritual de la religión, no se ofrece soporte al desafío educativo, de ello se deriva el enfrentamiento de las posiciones entre creyentes y no creyentes, $y$, en conclusión, se produce una situación de estancamiento. ¿Existe otra vía? Pienso que sí. Esta vía es la que pasa por los nuevos estudios sobre el tema de la "reflexividad" (Donati, 2010). La educación que tie- 
ne una inspiración cristiana debería reconfigurar su enfrentamiento con la modernidad sobre el terreno de la nueva "reflexividad", distinta de la moderna, que ha terminado en las profundidades de una autorreferencialidad vacía. Qué significa esto es lo que intentaré tratar brevemente aquí.

\section{Las causas profundas de la crisis educativa}

La pérdida de la capacidad de orientación de las instituciones de socialización (familia y escuela) es reflejo de las profundas transformaciones de las estructuras sociales y culturales. Sin embargo, no debemos ver solo este lado (estructural) de la medalla, es decir la incidencia de los procesos macrosocietarios sobre las situaciones singulares (las familias y escuelas singulares, y los mismos jóvenes, como productos de un "gran sistema" que los absorbe). Debemos saber ver también el otro lado de la medalla, es decir, los procesos microsocietarios en los que las personas singulares, familias y escuelas toman sus decisiones y con ello contribuyen a forjar la organización del contexto sociocultural, del que se debe decir cuál es el sentido educativo.

En resumen, las causas toman dos direcciones: 1) las transformaciones radicales del ambiente sociocultural que superan a las instituciones educativas y 2) los consiguientes procesos internos de las personas, las familias y las escuelas, consideradas como sujetos relativamente autónomos, los cuales no responden solo a los determinismos societarios, sino que contribuyen a configurar contextos de vida.

1. Las transformaciones del sistema sociocultural son patentes. Quisiera poner en evidencia algunos aspectos quizá no del todo obvios.

a. Han saltado todos los nexos simbólicos que daban sentido a la antigua concepción de la educación como e-ducere; la expresión latina aludía al hecho de traer fuera del niño al hombre maduro, pero esto presuponía un cierto horizonte cultural que atribuía de significados humanos a los comportamientos denominados "educados" sobre la base de una visión "naturalista" de la cultura (la cultura que imitaba la naturaleza). Hoy este horizonte ya no existe. Los nexos entre el elemento espiritual y el elemento automático de los comportamientos se han alejado y espaciado (Blaise Pascal diría que el espíritu y el autómata se han ido por su cuenta) puesto que no hay ya hábitos (habitus) que puedan considerarse por sí mismos virtuosos. La morfoestasis de los valores tradicionales y universales, que también había sobrevivido en la primera modernidad, viene a menos, $y$ de todas formas no mantiene ya la morfogénesis de las modalidades educativas.

b. Lo que hace crítica la educación es la pérdida de proyectividad, que es en gran parte "forzada", en el sentido de que resulta inevitable por el hecho de que nuestra sociedad ofrece a los jóvenes siempre menos oportunidades de realizar sus proyectos, profesionales y familiares, y, en general, proyectos de vida sensata. Las oportunidades se vuelven siempre más inciertas y arriesgadas.

Algunos estudiosos han dado un nombre a estos procesos de transformación: los han llamado "modernización reflexiva" (Beck, Giddens y Lash, 1999). Yo observo, sin embargo, que deberíamos sobre todo hablar de "fin de la modernidad", porque se trata de procesos que, bajo la etiqueta de una posterior fase de modernización, problematizan la misma modernidad, hasta el punto de erosionar las premisas sobre las que se basaba el proyecto emancipador y progresista de la primera modernidad.

Esto se ve en el clima socializador, sea de la familia o de la escuela, que se ha convertido en un momento de sociabilidad como fin en sí misma, "lúdica" en el sentido más 
genérico del término, en el que la educación se concibe como un aprender a estar junto a los otros respetando sus diferencias. Los factores de competencia (competición para alcanzar niveles más elevados de capacidades y habilidades), los factores de mérito, los proyectivos están prácticamente ausentes, a pesar de la buena voluntad de muchos profesores y también de muchos estudiantes.

2. Estos procesos macrosocietarios tienen su correlativo dentro de los sujetos (las personas concretas, las familias, las escuelas). Los reflejos en los procesos de socialización internos a los sujetos son:

a. El derrumbamiento del modelo de la socialización como "interiorización" (o "internalización") de un sistema cultural y social, que ha sostenido toda la concepción moderna de la educación (por ejemplo, el modelo parsoniano).

b. Las crecientes dificultades para vivir la educación como relación interpersonal entre padres e hijos, y entre profesor y alumno; las dificultades contemplan más en general la educación como creación de relaciones sociales válidas; dificultades para educar al individuo en el sentido de capacitarlo para tener relaciones sociales válidas consigo mismo, con los otros y con el mundo.

Nos encontramos de frente a una transformación epocal. Es preciso entender por qué y cómo ha tenido lugar una regresión histórica de enorme flujo que va del nacimiento de la escuela moderna, entendida como forma de disciplina social (véanse la Reforma protestante y la denominada Contrarreforma católica), a la escuela posmoderna en la que se da la búsqueda de la máxima variedad (pluralismo educativo) en la que la desviación se vuelve "normal" (Luhmann y Schorr, 1988).

Los distintos modelos de educación que se suceden en la historia (tabla 1) indican este camino.
Con el inicio del siglo XXI, se evidencia la crisis del modelo modernizado (socialmente llamado "posmoderno) de educación. En particular, la crisis afecta al modelo educativo sostenido por la ideología del multiculturalismo (Donati, 2008). Debemos preguntarnos, entonces, qué significa la educación en una "sociedad plural" (Scola, 2007).

Necesitamos otra escuela. Una escuela en la que los chicos puedan vivir la "realidad real", la "verdadera vida", y no la "vida virtual". Sabemos bien que, de hecho, ellos viven en un mundo virtual porque la sociedad ha creado para ellos un ambiente comunicativo (Internet, new media, etc.), que sobrepasa a las instituciones educativas familia y escuela.

Desde el punto de vista sociológico, este ambiente comunicativo es su realidad, más real que el de la familia y la escuela. J. Baudrillard la ha llamado híper-real, lo que significa que, para las nuevas generaciones, la vida verdadera es la de la ficción, a la que la realidad real se asemeja, en vez de al contrario. Es justo aquí donde debemos apuntar con el dedo.

No solo para desterrar lo negativo, sino sobre todo para ver qué podemos hacer de positivo, para hacer emerger lo positivo.

¿Qué hacer? La vía señalada es la de hacerse nuevamente conscientes de que la cuestión educativa se ha convertido en una cuestión antropológica. Esto quiere decir: los problemas y las soluciones educativas se buscan a partir de una recomprensión de cómo se entiende el ser humano, la persona humana, sus necesidades de desarrollo (personalización). ${ }^{6}$

La educación/formación humana debe concebirse como capacidad de relación sensata. Su función prevalente es la de desarrollar los potenciales humanos de la persona en todo el curso de vida. El

5 Así la llamaba Luigi Sturzo (2005)

6 Este es el análisis propuesto en el Informe del Proyecto cultural de la CEI, "El reto educativo", presentado el 22 de septiembre de 2009 en Roma (Comité Proyecto Cultural Cei 2009). 
Tabla 1. La evolución de la relación educativa

\begin{tabular}{|c|c|c|c|c|}
\hline Periodo & Formación como & Función prevalente & $\begin{array}{c}\text { Objetivo del procedimiento } \\
\text { educativo }\end{array}$ & $\begin{array}{l}\text { Posición de quien } \\
\text { aprende }\end{array}$ \\
\hline Hasta el siglo XVII & $\begin{array}{l}\text { Búsqueda de la } \\
\text { perfección (como } \\
\text { perfección moral de la } \\
\text { naturaleza humana) }\end{array}$ & $\begin{array}{l}\text { Construir el hombre } \\
\text { ideal (el mejor } \\
\text { hombre: el sabio, el } \\
\text { héroe, el santo) }\end{array}$ & $\begin{array}{l}\text { Desarrollar la razón y las } \\
\text { virtudes (para la felicidad) }\end{array}$ & $\begin{array}{c}\text { Dependencia } \\
\text { interpersonal del } \\
\text { "maestro", llamada al } \\
\text { absoluto, imitación de } \\
\text { lo verdadero, lo bueno, } \\
\text { lo bello }\end{array}$ \\
\hline $\begin{array}{l}\text { Desde el siglo XVIII } \\
\text { hasta la primera } \\
\text { mitad del siglo XX } \\
\text { (Primera modernidad) }\end{array}$ & $\begin{array}{c}\text { Formación para la } \\
\text { prestación (educación } \\
\text { moral como resultado } \\
\text { de la división del } \\
\text { trabajo) }\end{array}$ & $\begin{array}{l}\text { Preparar para el } \\
\text { sistema profesional } \\
\text { estratificado } \\
\text { (capacidad de } \\
\text { prestación) }\end{array}$ & $\begin{array}{c}\text { Aprender lo universal (para } \\
\text { elaborar lo particular que es } \\
\text { lo propio del experimentar } \\
\text { individual) }\end{array}$ & $\begin{array}{c}\text { Dependencia de una } \\
\text { organización formal, } \\
\text { especificación funcional, } \\
\text { utilidad, planes y } \\
\text { procedimientos }\end{array}$ \\
\hline $\begin{array}{l}\text { Segunda mitad del } \\
\text { siglo XX (segunda } \\
\text { modernidad o } \\
\text { posmodernidad) }\end{array}$ & $\begin{array}{l}\text { Capacidad } \\
\text { de aprender } \\
\text { (autorreflexión } \\
\text { funcional) }\end{array}$ & $\begin{array}{l}\text { Aumentar la } \\
\text { reflexividad (como } \\
\text { aplicación de un } \\
\text { acto a sí mismo) }\end{array}$ & $\begin{array}{c}\text { Aprender a aprender (aprender } \\
\text { como disposición para un } \\
\text { ulterior aprendizaje) }\end{array}$ & $\begin{array}{l}\text { Informal, contingente, } \\
\text { no emotivo, interactivo, } \\
\text { adaptativo }\end{array}$ \\
\hline $\begin{array}{l}\text { Inicio del siglo XXI } \\
\text { (inicios de la sociedad } \\
\text { dopo-moderna): } \\
\text { nuevos horizontes }\end{array}$ & $\begin{array}{l}\text { Capacidad de relación } \\
\text { sensata (por una vida } \\
\text { más humana) }\end{array}$ & $\begin{array}{l}\text { Desarrollar los } \\
\text { potenciales } \\
\text { humanos a lo largo } \\
\text { de toda la vida }\end{array}$ & $\begin{array}{l}\text { Desarrollar la personalidad } \\
\text { del alumno o de quien trabaja } \\
\text { a través de las relaciones (en } \\
\text { cuanto humanas) }\end{array}$ & $\begin{array}{l}\text { Personalizada, no } \\
\text { tangible, atenta a la } \\
\text { globalidad }\end{array}$ \\
\hline
\end{tabular}

objetivo práctico del procedimiento educativo es el de desarrollar la personalidad a través de relaciones adecuadas. Quien aprende no es sustituible. El sistema formativo debe organizarse como una red comunicativa inteligente que opera como guía relacional de quien debe aprender.

\section{Es fácil decirlo, ¿pero qué hacer concretamente?}

Se requiere un marco que no sea individualista, ni sistémico, sino relacional. El análisis relacional (véanse las cinco reglas de base: Donati, 1006a) nos enseña que, para comprender el éxito educativo, se necesita proceder así: a) primero, se trata de observar la educación como relación social, y después b) se trata de ver cómo los procesos macrosocietarios y los procesos microsocietarios se combinan en la generación de lo que llamamos "educación" como efecto emergente.

Se entiende que el efecto puede ser positivo o negativo. De hecho, hablamos de una buena o mala educación. El éxito depende de qué tipo de relación generativa se activa. Se supone que la mejor educación consiste en generar una socialización enten- dida como bien relacional: en resumen, si educar quiere decir "generar" en el sentido de la relación generativa, entonces se necesita presuponer que haya "alguno" (juna persona! Y no una cosa) que generar, el cual encuentra en tal relación la vía de acceso a sí mismo, teniendo por tanto la posibilidad de convertirse en sí mismo a través de los otros (el Otro significativo sobre el que el individuo se inspira como modelo o estímulo para su propia educación).

Las soluciones para afrontar la emergencia educativa no pueden privilegiar ni a los factores macrosistémicos (estructuras organizativas), ni a los factores microsocietarios (las relaciones personales), sino que deben equilibrarse a través de los procesos de "morfogénesis sensata" (Donati, 2009b). En otros términos, los factores estructurales e individuales pueden y deben interactuar de tal manera que se conviertan en posibles respuestas al problema de la emergencia educativa que sean "generativas" de sentido humano.

En otras palabras: se precisa adoptar el paradigma relacional de la educación y ver qué oportunidades puede ofrecer. 


\section{Un nuevo paradigma educativo: realista, relacional y reflexivo}

Si observamos la emergencia educativa con los ojos de los modelos de socialización denominados "tradicionales" (aquellos que han caracterizado la escuela desde fines del ochocientos, hasta casi 1970), lo que vemos es el venir a menos, el hundimiento, la disgregación del paradigma educativo que ha sostenido la primera modernidad, todavía imbuida de valores clásicos.

El paradigma educativo denominado "tradicional" (que en realidad corresponde al ethos de la primera modernización), tiene como objetivo una transmisión cultural que, sin embargo, está abierta a la innovación científico-tecnológica, pero al mismo tiempo está fuertemente anclada a un ethos moral en el que se confía para la disciplina, para evitar el caos. La escuela refleja y reproduce todavía una concepción de la virtud como habitus. A nivel funcional, es un modelo representativo, pero a nivel moral se basa en la internalización (interiorización) de la cultura de las generaciones precedentes por parte de las nuevas generaciones.

La modernización avanzada destruye este paradigma. La modernidad, reflexionando sobre sí misma, descubre que ya no tiene como ideal un modelo educativo conforme a la naturaleza. Al contrario. Todos los modelos educativos que se refieren al paradigma de la naturaleza se vuelven obsoletos. Vienen a menos todos los nexos, hasta entonces dados por supuestos, entre el sentido espiritual de los comportamientos y los modos habituales de acción (entre "el espíritu" y "la autonomía", como decía Blaise Pascal) (Panebianco, 2009); es decir, los hábitos que traducían el sentido espiritual de una sociedad en comportamientos morales habituales. Se cuestionan radicalmente las instituciones (Colozzi, 2009).

Se requiere un paradigma educativo que se base en las siguientes características: no ya en la simple transmisión cultural, sino en la reelaboración sensata de las tradiciones culturales; no ya en la formación de hábitos (habitus) a través de la repetición, sino estimulando la reflexividad personal (conversación interior) con la adopción de un modelo promocional de las capacidades personales y relacionales (coaching educativo).

Pero atención. No se trata de aceptar esa concepción de la educación que hoy se propone denominada "teoría de la modernización reflexiva" (Beck, Giddens, Lash), que es en muchos sentidos engañosa. Efectivamente, esta teoría entiende la reflexividad solo como un modo de ser más consciente de los riesgos y de las desorientaciones en que nos debatimos, es decir como conciencia infeliz por el hecho de que los problemas no tienen soluciones. Esta propone que, a pesar de esta condición infeliz, el individuo puede reivindicar la afirmación de sus derechos y así emanciparse de todas las constricciones sociales que lo limitan en sus posibilidades de autoindividualización. Al contrario, yo mantengo que los modelos formativos deben hoy interrogarse sobre cómo modificarse a sí mismos para encontrar el sentido originario, fontal, generativo, de la educación como relación social. En definitiva, nuestra sociedad se encuentra en la necesidad de elaborar un paradigma educativo realista que sea relacional y reflexivo.

\section{Realista}

La transformación educativa debe tener un sentido realista, o sea debe tener una concepción de la educación como modalidad formativa inspirada en el realismo crítico antes que en el constructivismo, hoy en boga, que entiende la socialización como un proceso basado en el relativismo cognitivo y ético.

La concepción realista de la educación se basa en la siguiente observación fundamental: en la educación, la mente humana aprende mucho más del "testimonio" —es decir, del experimentar (sentir, tocar, ver) la realidad- que llega de los sentidos (ver desde la práctica en acto, vivir una cierta relación con otra persona, un amigo, un profesor), que de 
la definición conceptual que viene formulada en el discurso y pensada en el Yo. El Yo del niño se forma en la práctica, primero natural y luego social, antes que en el uso de una lengua y de una cultura (es decir, precede la conciencia basada en el Mundo 3 de Karl Popper).

\section{Relacional}

Justo porque la experiencia práctica (incluido el testimonio recibido) precede a la reflexión cognitiva, el Yo se constituye a través de la relación social. La razón aprende de la experiencia de modo relacional respecto a su ambiente.

Este modo de pensar, digamos, el paradigma relacional, ha sido apuntado claramente como base de una nueva cultura civil en la encíclica Caritas in veritate (CV, 29 junio 2009). En la base de esta afirmación está la idea de que permanece la verdad perenne según la cual la dignidad humana consiste en la filiación divina, y es igualmente verdad que hoy cambia el sentido (histórico, cultural, contextual) de aquello que es humano. El escenario nos pone frente a un complejo de degradaciones de todo tipo, especialmente en el campo de la manipulación de la vida humana y de la familia, así como en tantas emergencias, desde la educación, a la desocupación, a la negociación de derechos humanos fundamentales en tantas partes del mundo. No se puede afrontar este nuevo escenario sin una adecuada antropología ("La cuestión social se vuelve radicalmente una cuestión antropológica", CV, n. 75) y sin que tal antropología sea capaz de proyectarse más sobre la entera sociedad, es decir, sobre todas las relaciones sociales en las que entre en juego la vida humana. La vía que Benedicto XVI propone puede ser, desde mi punto de vista, llamada "relacional" por el hecho de que es en la categoría de la relación donde se busca la solución.

La criatura humana, en cuanto de naturaleza espiritual, se realiza en las relaciones interpersonales. Cuanto más las vive de modo auténtico, más madura también la propia identidad personal. No es aislándose como el hombre se valora a si mismo, sino poniéndose en relación con los otros y con Dios. La importancia de tales relaciones se vuelve por tanto fundamental. Esto vale también para las sociedades. Es, por tanto, muy útil para su desarrollo una visión metafísica de la relación entre las personas ( $C V, n$. 53).

Y un poco más adelante: "La revelación cristiana sobre la unidad del género humano presupone una interpretación metafísica de lo humano en la que la relacionalidad es elemento esencial" (CV, n. 55).

Por tanto, la educación que niños, jóvenes y adolescentes necesitan es aquella que ve el constituirse del Yo (la identidad personal y social) en las relaciones, con las relaciones, a través de las relaciones, porque la experiencia relacional (la experiencia vital, el ponerse en relación dando testimonio práctico) precede la definición cognitiva y la reelaboración conceptual de la identidad humana con sus intereses, prioridades y proyectos.

\section{Reflexivo}

La educación del niño/joven se forma en las relaciones con la realidad mediada por la propia reflexividad personal (aquí vale la lección de Margaret Archer), ${ }^{7}$ pero también por la reflexividad que resulta accesible en el ambiente cultural y organizacional en que se encuentra.

El nuevo paradigma requiere una reorganización cultural y estructural, sea de la familia o de la escuela (y de los sistemas formativos en general) que adopte una concepción distinta y plural de la reflexividad humana (que yo clasifico en: personal, social y organizativa).

Esta reflexividad comienza en la familia (la familia reflexiva), sigue en la escuela (escuela reflexiva) y se sirve de un contexto interno a la familia y a la

7 Véase el esquema circular Yo-Mi-Nosotros-Tú de Archer (2006). 
escuela donde se encuentran las redes y las asociaciones familiares (redes sociales reflexivas).

Es toda la sociedad, más allá de la alianza educativa entre los sujetos del proceso socializador, la que debe hacerse reflexiva. La alianza educativa es viable solo si se concibe como una forma de construcción de redes de relaciones sociales que valoran el capital social de la escuela a través del capital social de las familias y del resto de subjetividades sociales involucradas en esas redes que llamamos alianzas locales puesto que están hechas de empresas, fundaciones, entes locales, organizaciones privadas y tercer sector arraigadas en el territorio.

\section{Una nueva configuración institucional de la escuela como "servicio relacional" y como "escenario de reflexividad"}

Debemos saber ver el nuevo escenario que se perfila en el horizonte para la escuela infantil, de primaria y secundaria. Se puede ver si partimos de la observación de que las nuestras no son escuelas reflexivas, y mucho menos son un servicio relacional. No crean amistad ni vínculos sólidos y significativos. $^{8}$ No hacen crecer la reflexividad. ¿Qué hacer?

Deben convertirse en un servicio que tenga las siguientes características: ser relacional y reflexivo. Veámoslo con mayor detalle.

\section{a. La escuela como servicio relacional}

¿Cómo debemos entenderla?

Un servicio a las personas (como la educación) es relacional si, y en la medida en que, se organiza de tal modo que define sus objetivos en términos relacionales y si los persigue con medios y normas de tipo relacional, teniendo como modelo de valor el de la promoción de la misma relacionalidad (entendida como capital social —hecho de confianza, coo-

8 Estos resultados empíricos se señalan al final de la investigación que hemos realizado en los años noventa: cfr. Donati y Colozzi (1997). peración y reciprocidad-que alimenta la creación de capital humano). Bajo el aspecto organizativo, un servicio es relacional no solo porque opera involucrando a todos los actores sociales interesados en la consecución de la finalidad del servicio, sino porque opera sobre sus relaciones - con ellas y a través de ellas- como medio y objetivo del servicio mismo. Debe, por tanto, saber "ver" las relaciones, debe saber analizar y actuar sobre ellas respetando su naturaleza relacional, antes que transformándolas en otras "cosas".

En el caso específico de la educación, un servicio escolar es relacional si y en la medida en que responde a los siguientes requisitos (figura 1). ${ }^{9}$

G) El objetivo del servicio relacional es el de hacer al alumno capaz de relacionarse de modo satisfactorio consigo mismo, con los otros y con el mundo que le rodea. De hecho, se dice que el fin de la educación sea el "bienestar" (well-being) del niño/joven/ adolescente, pero esto no es exacto. El bienestar es el output (la consecuencia, el resultado) de una buena educación, no lo contrario. El bienestar del menor no es un estado final, ni mucho menos una condición del individuo como tal, sino un "bien" que emerge de las relaciones que el menor tiene con el mundo circundante. La hipótesis es que el potencial verdaderamente "relacional" de un servicio educativo para la infancia se desarrolle en la construcción de una relación de colaboración y de confianza entre educadores/as, niños y padres. Particular importancia tiene la capacidad del servicio para generar, junto al bien relacional interno a la escuela, también el bien relacional de las familias de las que provienen los niños y también las solidaridades asociativas entre las mismas familias.

A) El servicio requiere instrumentos y recursos (materiales y humanos) válidos para alcanzar el objetivo. Lo que significa que, más allá de las exigencias

$9 \quad$ El análisis relacional propone valorar los casos que son objeto de estudio con referencia al esquema relacional AGIL, el cual es "brújula" para la observación e interpretación sociológica. 
financieras y tecnológicas, deben ser antes que todo medios hechos de entidades relacionales, más bien de las relaciones mismas que el alumno tiene en su situación. En todo caso, los recursos deben provenir de la "correspondencia" de los sujetos cointeresados y, en particular, de la utilización de recursos familiares debidamente reconocidos, promocionados y recompensados por las instituciones.

I) Un servicio relacional debe operar con reglas que responden al principio de la subsidiariedad hacia el alumno, según una lógica reticular (no jerárquica, ni de equivalentes funcionales). La gobernancia del servicio y la definición del contexto regulador se desarrollan de modo coordinado entre los sujetos que se mueven y concurren en la realización de un objetivo común, con particular atención en la subsidiariedad a la familia.

L) El servicio relacional debe su cualidad y capacidad de incidir sobre la realidad al hecho de basarse en la promoción de un modelo cultural que reconoce y favorece los procesos de valoración de la relacionalidad entendida como un actuar recíproco que se orienta con base en un sentido suprafuncional del que dependen la humanización de la persona, el reconocimiento de sus derechos, así como de sus obligaciones (Donati, 2009a, p. 133).

Un servicio como relación social es, por tanto, el efecto emergente de un mix de recursos aportados por una pluralidad de sujetos sociales en red, movilizados para responder a un problema específico y capaz de generar bienestar operando con las relaciones y sobre relaciones, $\mathrm{y}$, por tanto, promoviendo una cultura de las relaciones.

En Italia, el sector de servicios educativos, desde el de la infancia al de la adolescencia y otros, ha estado siempre "orientado al individuo", conceptualizado siempre más como "ciudadano" (los niños, se dice, son ante todo "ciudadanos"). La familia se ha dejado al fondo de la escuela, es en todo caso una "presencia de fondo". Se reclaman modelos de servicios en los que la familia no esté limitada por una re-

\section{Figura 1. Configuración relacional de un servicio educativo para la infancia-adolescencia}

\author{
$G$ (meta) \\ Educar consiste en desarrollar \\ las capacidades del \\ niño/adolescente de tener \\ relaciones sensatas consigo \\ mismo, con los otros y el mundo \\ social que le rodea
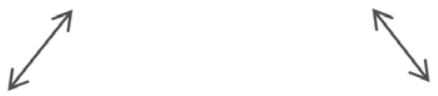 \\ $A$ (medios) \\ Instrumentos que sirven \\ para perseguir el \\ fin/objetivo situado \\ mediante el potenciar de \\ las relaciones sociales \\ en juego

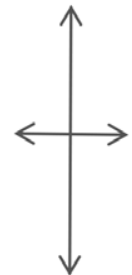 \\ I (reglas) \\ La acción educativa \\ debe ser subsidiaria \\ (debe ayudar al \\ alumno a hacer aquello \\ que debe hacer \\ haciéndose siempre \\ más autónomo)
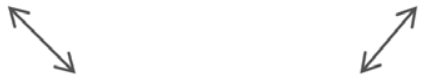 \\ $L$ (criterio valorativo) \\ La capacidad de la relación instaurada \\ entre profesor y alumno de desarrollar las \\ cualidades personales del alumno
}

ferencia indirecta, de contexto, sino que se convierta en sujeto activo, protagonista y corresponsable del servicio. Pero las políticas permanecen fuertemente categorizadoras, por categorías abstractas de infancia, adolescencia, etc., que en su "práctica" no se abren todavía a un modo de entender -y sobre todo de practicar- los servicios en sentido relacional.

La ventaja de estos últimos es la de valorar el capital social, de las escuelas, de las familias y de las redes sociales que están entre ellas. Si entendemos el capital social como relaciones de confianza, cooperación y reciprocidad, entonces son justo estas cualidades relacionales las que hacen una buena educación y sirven para la formación de los talen- 
tos y las habilidades personales que constituyen el capital humano. ${ }^{10} \mathrm{El}$ malestar de los adolescentes y jóvenes, así como la dispersión escolar, pueden ser evitadas de mejor manera adoptando la perspectiva del capital social (Donati, 2006b).

\section{b. La escuela como escenario de reflexividad}

La reflexividad de la escuela como forma social es un tema nuevo (si se distingue del tema del profesor o del profesional "reflexivo"). Una escuela es reflexiva en la medida en que es capaz de operar valorando el capital social, sea el interno (propio) o el de las redes (familiares y comunitarias) del entorno.

La escuela reflexiva es tal: 1) no solo porque cada uno (profesores y alumnos) hace bien su parte (sus cometidos), sino también, 2) porque cada uno se relaciona con los otros de tal manera que construye una red subsidiaria de relaciones reciprocas.

La reflexividad del organismo escolar está en valorar su modo reticular de operar según las modalidades del capital social. Este último consiste: a) en el capital social interno (capital social bonding), b) en el capital social de vinculación con las familias de los alumnos (capital social bridging) y c) en el capital social de unión (governance) con las otras escuelas a nivel de la comunidad territorial de referencia (capital social linking) (Donati y Tronca, 2008).

Para toda escuela deberemos poder analizar su capital social, bonding; bridging con las familias (cómo involucrarlas, cómo atraerlas de nuevo, cómo crear redes extraescolares con ellas), linking con el sistema integrado de las escuelas estatales y concertadas.

La libertad de elección de la escuela por parte de la familia es el prerrequisito fundamental, la primera condición para la viabilidad del modelo relacional reflexivo de escuela y de educación.

10 Para una mayor comprensión del capital social sobre el tema específico de la escuela y de las redes sociales entre escuela y familia, veáse Donati y Colozzi (2006).
Si tal libertad no viene asegurada, o no lo es de modo adecuado, nacen alternativas como las homeschools que se están difundiendo en América y otros países, las cuales no son un fenómeno de clase (de clase alta), no nacen por exigencias de mantener los privilegios, sino que responden a un problema de relacionalidad: los padres se dan cuenta de que la educación de los hijos implica una cierta relacionalidad que la escuela pública no realiza y se organizan en su casa.

De aquí proviene también la idea de que, si la escuela formal pudiera fracasar, quizás en un futuro próximo la escuela, así como nosotros la conocemos, podría también desaparecer, porque sería sustituida por formas socializadoras más satisfactorias en términos de capacidades educativas, dado que responden mejor a las necesidades de los individuos y de las familias.

La escuela como servicio relacional es aquella que sitúa en el centro de su reflexividad las relaciones internas que componen su compleja trama: las relaciones entre profesor y estudiante, entre profesores, entre estudiantes, entre profesores y familias, entre estudiantes y familias. Se trata de una configuración relacional que se diseña para producir bienes relacionales.

Un educador reflexivo sirve, pero no basta. Es la organización de la escuela la que debe volverse reflexiva.

El tema de la reflexividad -entendida como capacidad del pensamiento de extraer las consecuencias del objeto de su pensamiento- está hoy en el centro de un amplio debate en las ciencias filosóficas y sociales. Los efectos individuales y sistémicos de esta nueva conciencia se reflejan sobre los denominados custodios de la cultura, los científicos de la conciencia y los formadores/educadores, modificando las prácticas de adquisición, elaboración y transmisión del saber. El nuevo "actor social de la formación" es un profesional reflexivo que adopta métodos, técnicas, enfoques específicos para apli- 
car la reflexividad a la experiencia y al propio pensar, transformando radicalmente su relación con el cliente/usuario de la formación que asume un significado de reciprocidad y de intercambio dinámico entre identidades en construcción; paralelamente, se transforma el vínculo del profesional con las organizaciones de las que forma parte, en el sentido de una ampliación de los márgenes de creatividad en la elección de los lenguajes que va a utilizar, de los códigos interpretativos y de las reglas de uso."

Incluso, se subraya que la reflexividad del profesional no puede y no debe ser una actividad autorreferencial. Al contrario, la reflexividad personal y social que el profesor debe activar y realizar, si bien entendida como capacidad de actuar sobre sí mismo pasando a través de la relación con el Otro, sea para el profesor sea para el alumno, es el mejor antídoto contra la tan aclamada autorreferencialidad de los docentes.

En conclusión, para salir de la emergencia educativa es necesario adoptar una estrategia de subsidiariedad que se dirija a promover una escuela relacional y reflexiva.

\section{El rol de las asociaciones de padres}

De todo lo dicho hasta ahora, se deriva el hecho de que la emergencia educativa no pueda ser ni afrontada ni enfrentada sin comprender el nuevo y crucial rol que llegan a tener las asociaciones de padres.

11 El volumen a cargo de M. Colombo (2005) recoge las contribuciones multidisciplinares (sociología y pedagogía) que analizan el perfil del profesional reflexivo en el ámbito educativo: docentes, educadores de infantil, educadores de formación profesional, formadores de empresa, coordinadores de recursos humanos, evaluadores de la formación, etc., en el marco histórico de los cambios actuales (globalización descentralización y reforma) en Italia y en tres países europeos: Gran Bretaña, Bélgica, Noruega. Se ilustran también instrumentos "reflexivos y creativos" adoptados en varias situaciones formativas, como el portafolio de las competencias, la investigación-acción, el informe autobiográfico, el storytelling, el doble círculo interpretativo. Sin embargo, se trata más de reflexión de individuos que de reflexividad relacional.
Estas asociaciones tienen dos tipos de funciones: a) funciones de representación (movimiento en diálogo con las instituciones), y b) funciones de democracia deliberativa (las asociaciones familiares son stakeholder de los institutos y de la red escolar, si vemos las escuelas como organizaciones relacionales, sea en su interior o en sus relaciones externas). Hasta ahora, los sistemas escolares han reconocido solo de forma ligera y poco desafiante estas dos modalidades. Las cuales, por otra parte, en ciertos países, resultan incompatibles entre sí (en Italia no es así, pero solo porque ambas valen, de hecho, poco).

Una estrategia de subsidiariedad para salir de la emergencia educativa consiste en insertar las asociaciones de padres en la arquitectura general del sistema escolar y formativo a través del principio de subsidiariedad plasmado en tres o más dimensiones: i) como subsidiariedad vertical (en el sistema); ii) como subsidiariedad horizontal (entre sistema y su ambiente); iii) como subsidiariedad lateral (entre escuelas, independientemente del sistema).

Desde hace años decimos que se precisa un "pacto escuela-familia". Este pacto resulta siempre más urgente, pero al mismo tiempo tiene un nuevo horizonte, que es el de las redes siempre más amplias de sujetos que deben, desde mi punto de vista, afrontar la emergencia educativa. Estas redes sociales que yo llamo Alianzas locales para los servicios educativos (sobre el modelo de las alianzas para la familia creadas en Alemania), tiene como objetivo sensibilizar a todos los actores locales sobre la atención educativa. Cada uno puede contribuir de una manera: hospitales, negocios, cines, ludotecas, empresas, bibliotecas y hemerotecas, servicios públicos, etc.

La pregunta fundamental es: ¿para qué sirven las asociaciones de padres, y, en general, las asociaciones familiares, si no es para ser sujetos protagonistas, activadores y catalizadores de estas Alianzas? $\mathrm{El}$ valor social añadido que dan a la sociedad no consiste solo en producir capital social y solidaridad (mutualidad) interna, sino también y sobre todo 
capital social y solidaridad para la comunidad local circundante. En Italia, debemos entender cómo valorar su capacidad, porque estamos todavía dentro de una regulación tutelar de las asociaciones, mientras por otro lado se ha pasado desde hace tiempo a una regulación competitiva y últimamente también a formas de regulación partnerial, que han valorado mejor la subjetividad social de las asociaciones de padres y familiares, y su rol civil.

Incluso, como he intentado mostrar en varios escritos e investigaciones, Italia tiene su peculiaridad en el estudio y en la promoción de las asociaciones familiares en Europa.

Hoy nosotros nos interrogamos de nuevo, a la luz de la experiencia madurada en estos años, sobre el sentido de hacer "asociaciones familiares", en particular entre padres que desean tener escuelas que formen a sus hijos a la luz del sentido cristiano de la vida humana.

Una asociación de familias es un hecho comunitario y, al mismo tiempo, contractual. Todo contrato tiene bases no contractuales, que hacen referencia al contenido "comunitario" (presente también en las formas "societarias" que no sean de business puramente instrumental), el cual, en el caso de la temática familiar, parece claro y evidente para todos, pero quizás no siempre lo es.

Un contrato como el de una asociación de padres que se quieran hacer responsables de la gestión de las escuelas requiere necesariamente la adhesión a valores comunes que legitiman plenamente, y sin reservas, el sentido, la fuerza y la proyectividad.

El "pacto asociativo" revela la gran fuerza de la asociación. Es su punto de mayor consenso y de máxima convergencia. Su sentido está en recordar que la asociación es una alianza entre las familias que se unen "para ayudarse y ayudar", no solo a las otras familias ya presentes, sino también a las que son socias potenciales.
Incluso las asociaciones de padres están siempre dispuestas a hacer frente a los dilemas que se encuentran. Desde el punto de vista sociológico, el dilema de fondo puede ser expresado con esta pregunta: ¿las asociaciones de padres con fines educativos consiguen hacerse sujetos (socios) de un proceso "sociativo" (asociación significa ad-socius) que, mientras confirma la propia inspiración cultural, consigue darse una nueva identidad y una organización autónoma, desde su propio interior? ¿Son capaces de ver las nuevas exigencias de subjetividades sociales, como la exigencia de proyectar escuelas que sean servicios relacionales y reflexivos, en el cuadro de nuevas alianzas locales para la escuela?

Este, bien visto, es el problema de una sociedad civil que no quiere incurrir en la denominada "solución hobbesiana del orden", la cual consiste en el hecho de que, cuando una pluralidad de sujetos individuales no se fian recíprocamente y entran en conflicto, recurren a un poder externo en quien se delega la autoridad con el fin de que proteja a cada uno de posibles intrusiones, constricciones o violaciones por parte de los otros "socios".

La modernidad, como sabemos, está toda dentro de la solución hobbesiana, que es la de un contrato entre socios que garantizan la propia libertad alineando la originalidad y la autonomía a un poder superior (el Estado), que debe legitimarla con el fin de poder ser ejercitada. Decir, por tanto, que las asociaciones de padres y familias deberían buscar otra vía, otra solución, para afrontar la emergencia educativa, no es decir ciertamente poco: es, simplemente, ir contra toda lógica de la modernidad. ¿Es esto posible?

Aquí reside, justamente, la apuesta. La identidad de las asociaciones de padres con finalidades educativas se somete hoy a esta pregunta. Para responder a los retos que plantea, estas asociaciones familiares deben aclarar los escenarios en que se mueven y los dilemas que pretenden afrontar: su futuro depende del hecho de definirlos de un modo u otro, de construirlos de un modo u otro. 
En el presente escrito intento precisamente definir los escenarios que emergen como ineludibles, y las elecciones que comportan, con todas las posibles consecuencias que pueden derivarse.

\section{Las asociaciones familiares de primer y segundo nivel: ¿cómo hacerlas sujetos de una nueva sociedad civil?}

Asociar las familias singulares es una tarea de las asociaciones de primer nivel. Asociar las asociaciones es tarea de una asociación de segundo nivel, etc. Pero las cosas no son así de simples. Porque proceder del primer al segundo nivel implica gestionar una relación más compleja que la relación del primer nivel. Si el segundo nivel no se sostiene adecuadamente por el primero encuentra crecientes dificultades (en términos de participación, consenso, recursos, eficacia en la consecución de objetivos). Viceversa, si el primer nivel no se sostiene adecuadamente por el segundo, las asociaciones singulares se sentirán aisladas, alejadas, incluso explotadas o maltratadas, en cualquier caso, no reforzadas. Unas y otras deberían ser conscientes de que una asociación de asociaciones inevitablemente modifica el cuadro en el que operan las asociaciones singulares. ¿Hacia dónde se debe ir? ¿Hacia una mayor integración entre las asociaciones singulares, aun a riesgo de perder la preciosa autonomía y la identidad de cada una, o hacia un planteamiento que se preocupe de limitar las funciones, el poder, el radio de acción de las asociaciones de nivel superior al segundo, para valorar al máximo las contribuciones de las asociaciones-miembros singulares?

Cuando dos tipos de asociaciones (de primer y segundo nivel) se enfrentan, la relación debe tematizarse en función de aquello que se quiere perseguir. Por poner un ejemplo, tomamos el caso del Fórum italiano de las Asociaciones familiares, nacido en 1992, que se ha analizado a este propósito (véase Donati y Prandini, 2003). Efectivamente, podemos decir que en el caso de esta asociación de asociaciones la tematización de cuanto he dicho ha sido hasta aho- ra insuficiente en algunos aspectos fundamentales, que tienen que ver no tanto con las motivaciones y los valores ideales, cuanto con la capacidad instrumental y reguladora del Fórum en tanto asociación de asociaciones.

No basta con el pacto asociativo sobre valores. Se precisa de un pacto asociativo sobre qué significa -y qué funciones asume-el hacer asociación entre asociaciones en cuanto organización que tiene exigencias representativas.

En términos más teóricos, no basta ya con un pacto sobre valores que legitiman los objetivos (eje L-G de la legitimación). Se requiere además un pacto sobre las reglas y sobre los medios propios y adecuados a la acción interna y externa del Fórum (eje I-A de la adaptación funcional en la relación internaexterna del sistema-Fórum frente a la esfera pública en la que opera).

Tanto reglas como medios deben ser adecuados a los objetivos y legitimados por los valores, y lo deben ser de manera compleja. Hay toda una coherencia interna entre las funciones que dan una identidad y una capacidad de acción a una formación social intermedia, y el Fórum nacional del que se habla no es excepción. Esta coherencia debe elaborarse a nivel interno teniendo presente que una formación social intermedia como es el Fórum, en este sentido, media, es decir interpreta, da voz, organiza y gestiona (no ya las asociaciones de primer nivel) la presencia pública como forma asociativa de las asociaciones singulares, que por otra parte deben mantener su propia identidad, plena autonomía y también la presencia directa en la esfera pública.

\section{Escenarios y dilemas de la educación entre "vía política" y "vía civil": ¿configuración lib/lab o configuración societaria?}

Las asociaciones de asociaciones familiares tienen frente a sí dos posibles estrategias. Escoger una u otra depende de cómo "se define la situación" 
(expresión que debe entenderse en un sentido sociológico), sea en el presente o en el futuro, es decir, del escenario en el que se mueve, $y$, por tanto, del hecho de definir correctamente los dilemas y las opciones que los dos escenarios implican, de tal forma que puedan prever de manera racional y sociológicamente correcta sus posibles consecuencias.

Desde mi punto de vista, los dos escenarios son el de la sociedad lib/lab y el de la sociedad asociativa. Los describo brevemente.

\section{$1^{\circ}$ escenario $l i b / l a b$}

En el primer escenario la sociedad se ve, en continuidad más o menos relativa con la modernidad, como el espacio en el que los individuos, libres y democráticos, se encuentran con iguales oportunidades de ejercitar sus derechos individuales, limitados solo por las obligaciones que se derivan de respetar los derechos de los otros. Llamo lib/lab a esta visión de la sociedad porque se basa en el compromiso entre las libertades del mercado (lado lib) y los controles para la igualdad asegurada del Estado (lado lab).

Es la escuela del pluralismo amorfo (la cual ha emergido de la investigación empírica sobre las escuelas estatales en Bolonia) (Donati y Colozzi, 2006): en estas escuelas, el individuo es solo un evento de la estructura social y cultural (porque la secuencia del proceso de socialización es la siguiente: estructura $\rightarrow$ individuo $\rightarrow$ estructura).

Yo defino como lib/lab un framework conceptual que es común a la mayor parte de los pensadores liberales y socialistas (J. Rawls, R. Dahrendorf, A. Giddens son solo algunos ejemplos). Representa un compromiso entre dos matrices culturales diversas, una individualista y la otra colectivista, que se expresa en forma de fusión central entre agency (elección o acción individual libre = lado lib) y estructura (ligamen, vínculo o condicionamiento estructural = lado lab).
Tal framework concibe la equidad social como oferta de iguales oportunidades de vida para todos (incluidas las hipotéticas futuras generaciones) en el cuadro de un pacto social. Tal pacto consiste en conceder el máximo de libertades utilitaristas a los individuos a condición de que sus comportamientos sean compatibles con los de los otros, en relación con un precio aceptable de equilibrio complejo entre consumo y conservación de recursos. Se trata de un compromiso entre mercado y sistema político democrático que se basa en tres cuestiones fundamentales: 1) aceptar la distinción entre libertad negativa (libertad "de") y libertad positiva (libertad "para" o "por"), según la acepción de Isaiah Berlin; 2) asignar la libertad negativa al mercado y la libertad positiva al Estado; 3) limitar la libertad (negativa) individual del mercado con la libertad (positiva) colectiva del Estado (o sistema político-administrativo). Todos estos asuntos son discutibles. De hecho: 1) la distinción entre los dos tipos de libertad es solo analítica y no empírica, porque de hecho ninguna libertad es solo negativa o solo positiva; 2) asignar la libertad negativa al mercado supone que dicha libertad sea privatizada, y, al contrario, asignar la libertad positiva al Estado supone que esta sea colectivizada; 3 ) atribuir los dos tipos de libertad respectivamente al mercado o al Estado conduce a una cosificación de los conceptos y de las prácticas sociales, con consecuencias inaceptables (por ejemplo, se llega a negar que el mercado pueda promover también libertades positivas y no se ve que también el Estado promueve libertades negativas).

Se trata de un framework que presenta selecciones no aceptables, sobre todo porque hace indiferentes o anula las relaciones familiares y entre las generaciones, y de este modo lleva la cuestión relativa a las políticas familiares al terreno de la indecisión.

En este escenario, las asociaciones son legitimadas para actuar como formas de representación de derechos entendidos como intereses, desde el 
momento que las identidades (culturales) deben permanecer como hecho privado. El lib/lab, de hecho, opta por la neutralidad o indiferencia ética de la esfera pública, salvo obviamente los derechos de igualdad entre los ciudadanos singulares y de solidaridad social hacia los más débiles. La sociedad civil se entiende como el desplegarse de los grupos de interés, no solo en sentido económico, sino también social (por ejemplo, como titulaciones de welfare). Los grupos de interés se engloban bajo la etiqueta del "pluralismo democrático" y forman aquellos que son llamados los sujetos colectivos de la esfera pública.

Tomamos el caso del Fórum italiano de las asociaciones familiares. Este, como las asociaciones singulares que lo forman, se concibe, legitima y trata como simple grupo de intereses y de presión. En resumen: el Fórum es aquí plenamente legitimado para actuar como organismo representativo de los intereses, mientras debe mantener sus instancias de identidad cultural.

Las ventajas que el Fórum puede tener son las de ser efectiva y eficazmente reconocido en estos términos, es decir, de poder influir sobre las políticas sociales (en sentido lato) dentro de los límites de este ordenamiento. No obstante, todo discurso sobre la subjetividad social de la familia, como todo discurso sobre las subjetividades asociativas, puede apreciarse en la esfera pública como una visión de fuerte carga ideológica, emotiva y unitaria, incluso también valorativa, pero siempre y solo como una visión "particular" que no puede aspirar a valor universal, por tanto, no puede convertirse en regla pública, sino que debe permanecer en la esfera de lo privado.

\section{$2^{\circ}$ escenario societario o asociativo}

En el segundo escenario la sociedad es vista, en discontinuidad más o menos fuerte con la modernidad, como espacio de relaciones entre sujetos individuales y asociativos que, sin eliminar las características de libertad y democracia, actúan con vistas a una ciudadanía activa y contextualizada ("profunda" como dice Clarke, 1996), de la que son titulares no solo los individuos, sino también sus formaciones sociales intermedias (Hirst, 1999a, 1999b; Viola, 2001). Las libertades se conciben no solo como "libertad de", sino sobre todo como "libertad para" (es decir en positivo), y la democracia se entiende como forma asociativa de personas que se deben encontrar ciertamente con iguales oportunidades para ejercitar sus derechos individuales, pero no solo limitadas por las obligaciones que se derivan de respetar los derechos de los otros, sino también por deberes de solidaridad que se ejercitan en esferas particulares que apuntan a funciones universales.

Llamo asociativa o societaria esta visión de la sociedad porque se basa no ya sobre el compromiso entre mercado y Estado, sino sobre una sociedad civil que es prioritaria respecto a uno y otro, aun cuando deba operar en constante sinergia con ellos.

El término "societario" quiere enfatizar un doble hecho: 1) que se trata de un carácter que atraviesa toda la sociedad (afecta a todas las esferas de vida, trabajo y relación; según el término inglés societal), 2) y consiste en el hecho de que la sociedad surge solo cuando las relaciones recíprocas suscitadas por ciertos motivos, valores, identidades e intereses, son puestas en marcha por actores que se orientan a una empresa social común, y de sus interacciones-intercambios surge, como fenómeno emergente (Wechselwirkung), una relación asociativa que tiene una base comunitaria. Lo que significa que tal carácter ("societario") puede comprenderse con una teoría sociológica generalizada (denominada relacional), a la cual le corresponde la tarea de mostrar el carácter estratificado y morfogenético de las formaciones societarias que emergen.

En este caso, las asociaciones son legitimadas para actuar no solo como formas de representación de los intereses, sino también como sujetos de identidades culturales que dan sustancia a la esfe- 
ra pública. La vía asociativa, de hecho, no mantiene ni válida ni deseable la solución con base en la cual la esfera pública debería inspirarse en criterios de neutralidad o indiferencia ética, desde el momento que, de un modo u otro, la esfera pública es y debe ser siempre éticamente (y también religiosamente) cualificada. En tal sentido, los valores de igualdad entre los ciudadanos singulares y los valores de solidaridad social hacia los más débiles no se dejan a la negociación entre Estado y mercado, sino que vienen éticamente cualificados por una sociedad civil que se constituye como esfera pública a la cual también el Estado y el mercado deben rendir cuentas. La sociedad civil, de hecho, se entiende aquí no como un desplegarse de múltiples grupos de intereses, sino como "asociación de asociaciones y de comunidades", las cuales deben saber distinguir entre lo interno y lo externo, en clave de responsabilidad y de transparencia pública. Los grupos de interés y de identidad llegan, por tanto, a formar una "democracia plural", en la cual actúan como sujetos intermediarios entre los puros individuos y la colectividad.

En este escenario, el Fórum de las asociaciones familiares, como las asociaciones singulares que lo forman, puede concebirse, legitimarse y tratarse de manera conforme a las redes asociativas con miras a una "ciudadanía" propia, es decir, un complejo propio de derechos-deberes de ciudadanía. En resumen: el Fórum sería aquí plenamente legitimado para actuar no solo como organismo de representación de los intereses, sino como sujeto de identidades culturales que ejercitan una ciudadanía propia (denominada societaria) a través de la membership asociativa (Lichterman, 2002).

En este caso, las ventajas que el Fórum puede tener son las de poder ser y actuar como un sujeto social ("sujeto asociativo") que no solo puede influir sobre las políticas sociales (en sentido lato) a través del trabajo de negociaciones en el cuadro lib/lab, sino que puede diseñar y realizar sus propias políticas sociales. El discurso sobre la subjetividad social de la familia, así como el discurso sobre las subjeti- vidades asociativas, no recibe solo una apreciación teórica por la idealidad que contiene, y siempre a cambio de que permanezca dentro el rol marginal de lo privado, sino que se convierte en fundamento de una sociedad civil en la cual las esferas "particulares" persiguen objetivos "universales". Y así hacen las reglas del vivir en común en la esfera pública. En este caso, el Fórum estaría llamado a hacer confluir sus energías en primer lugar para su crecimiento asociativo interno y a partir de ahí, después, para ejercitar funciones de representación.

Respecto a estos dos escenarios, el Fórum, obviamente, no tiene las mismas oportunidades, porque el escenario lib/lab es hoy históricamente y en gran medida dominante, y esto lo condiciona con fuerza. Es más, necesita reconocer que el escenario lib/lab está prácticamente aceptado -también de forma inconsciente- por buena parte de los mismos afiliados al Fórum. Incluso, en principio, el Fórum podría tomar una u otra vía. Es difícil, en todo caso, "estar en el medio", porque la configuración lib/lab y la asociativa (o societaria) tienden a absorber cualquier otra alternativa y polarizan hacia sí las fuerzas presentes. Oue, en Italia, la segunda vía sea prácticamente ignorada no asombra, siendo el sentido asociativo muy raramente originado por vía asociativa.

Si se define la situación en los términos del primer escenario, entonces las elecciones se conciben según la que yo llamaría la "vía política": el Fórum se inscribe en el juego lib/lab como uno de los varios actores que buscan un puesto en los compromisos entre Estado y mercado. Si se define la situación en los términos del segundo escenario, entonces las elecciones se conciben según la que yo llamaría la "vía civil": el Fórum destaca y apuesta por su identidad de sujeto de la sociedad civil.

Los dilemas entre la vía política y la vía civil no son una cuestión ideológica, como alguno podría estar tentado a sostener. Mucho menos son una cuestión de derecha y de izquierda (siendo por otra 
parte estas etiquetas actualmente privadas de un significado unívoco). Alguno podría estar tentado a pensar por analogía con la distinción entre una vía institucional y una vía movilizadora, o entre las asociaciones como instituciones-aparatos y como movimientos sociales, y similares. Pero tal analogía no tiene mucho que ver con cuanto quiero decir aquí. En todo caso, algo más interesante podría encontrarse con las asociaciones cooperativas y sus federaciones (Johnstad, 1997).

A mi parecer, de todas formas, los susodichos dilemas son esencialmente una cuestión de diversas estrategias de identidad y de intereses que se hacen valer respecto a dos visiones diversas de la esfera pública.

En el primer escenario, la esfera pública se concibe de manera "hobbesiana": son los individuos los que cuentan y el sistema se gestiona como expansión de las libertades individuales (negativas) limitadas por el control del sistema político igualitario. El Fórum, a la larga, se convierte en un lobby, y las asociaciones singulares se convierten en actores marginales, porque las concibe como organizaciones de "voluntariado", como sujetos de beneficencia antes que - como la mayor parte de ellas es o podría convertirse en un futuro- como organizaciones de multistakeholders (Borzaga y Mittone, 1997). No se descarta que, como los datos empíricos de esta investigación confirman, el escenario institucional lib/lab transforme las asociaciones en "comunidades privadas" que segregan a los grupos sociales, los fragmentan y hacen cenizas la sociedad (algo similar se ha puesto de relieve en América) (Bell, 1995). El proyecto family for family, que tiene tantas otras intenciones (precisamente esa, societaria, de construir redes familiares a través de redes familiares activando procesos de intercambio altruista alargado), podría superar esta deriva, y convertirse en una forma de beneficencia a distancia.

Para salir de estos equívocos, se precisa distinguir entre el don como acto de beneficencia y de puro voluntariado, incluidas las formas de encuentro entre familias como testimonio de una espiritualidad religiosa profunda (Boffi, 2001), que son tan queridas por la lógica lib/lab, y el don como modalidad de intercambio social (restringido y alargado, mutuo y público) (Caillé, 1998; Godbout, 2000), que funda las redes de reciprocidad y la misma democracia avanzada (Chanial, 2001), la cual está en la base del enfoque societario. ¿Pero las asociaciones familiares tienen claras estas distinciones? ¿No es quizás verdad que muchas de ellas se conciben como formas de voluntariado y de testimonio, sin ver las propias funciones societarias? Hay aquí más de una sugerencia para comprender cómo el código simbólico del don, propio de la familia, no sea el de un gesto voluntarista o de beneficencia, y tampoco de solo testimonio, sino una regla de vida social, es decir, de vida social.

Aquí tocamos la diferencia con el segundo escenario, en el que la esfera pública se concibe en cambio como lugar de encuentro entre realidades originarias (sujetos sociales) que deben construir un discurso relacional común. Respecto al escenario lib/lab, son completamente diversas las ideas de libertad y de orden social, así como son diversas todas las otras ideas relativas a los valores fundamentales de la existencia y co-existencia humana, del bien común, de las virtudes sociales y personales, así como de todas las buenas prácticas de sociedad. En una palabra, aquí la regla de oro es la que configura la sociedad como una "comunidad de comunidades" (Etzioni, 1996). La idea es la de una sociedad civil que se autogobierna con espíritu cívico y una fuerte mutualidad. El sentido moral de esta vía indica cuántas y cuáles sean las dificultades que esta presenta respecto a la primera. Es indudable que el Fórum siente la atracción, ¿pero cómo responde? Que el Fórum sienta también el peso de los condicionamientos lib/lab y no consiga salir de sus vínculos no es ciertamente algo que pueda ser motivo de culpa, sino en todo caso de comprensión de los enormes desafíos 
con que se encuentra. Lo importante es comprender bien la vía que hay que tomar.

En el Fórum existen asociaciones que son realmente conscientes de ser formas de organización social que median el origen y la destinación de los dones (en el sentido entendido por Osti, 2000). Pero son una minoría respecto al total de las asociaciones. En todo caso, cuando esta conciencia está presente y operante, las dinámicas que se ponen en marcha muestran que este mundo asociativo puede concretamente servirse de la ética del don como modalidad alternativa a la asistencial del welfare y la de la mercantilización de las relaciones sociales. Se ve cuando la acción asociativa realiza circuitos de don que no son ni particularistas ni incondicionales, sino dados de modo personalizado según la ética del don mismo. En estos casos, las asociaciones son efectivamente agentes de circuitos sociales originales que ponen en marcha los dones como mix entre particular y universal, en circuitos de intercambio que están entre los mundos vitales y las expresiones asociativas de la realidad civil. Son, estas, las asociaciones que se conciben como sujetos de una ciudadanía societaria entendida como ciudadanía plural de las autonomías sociales. Es entonces cuando persiguen bienes particulares a través de una acción colectiva, organizada de manera asociativa, que mantiene y promueve las finalidades particulares singulares en un marco cultural de reciprocidad y subsidiariedad, antes que recurrir a soluciones de redistribución y de intercambio mercantil o de asistencialismo paralizante. Pero estos casos, como he dicho, de hecho son todavía muy pocos.

Para recapitular. Me parece que falta todavía una comprensión de la perspectiva desde la cual responder al reto educativo. Esta respuesta implica y remite a una nueva "lectura" o "visión" de la sociedad y con ella del hombre. No se trata de una lectura idealista o idealizada de la sociedad. No proviene "de arriba" como tampoco proviene "de abajo", sino sobre todo del ser íntimo de las cosas. No es la expresión de cualquier "sujeto", ni de cualquier "siste- ma". Es la visión que proviene, fundamentalmente, de una actitud atenta al carácter "emergente" de las relaciones sociales en cuanto humanas. Esta actitud hacia lo social nace de un sentimiento de valoración y respeto hacia aquello que manifiesta la verdad (la verdadera riqueza) del hombre y de una elección no manipulada en sus límites.

Desde mi modesto punto de vista, esta visión consiste en una "interpretación relacional de la sociedad". Solo esa permite comprender a fondo la dinámica actual de la sociedad sin quedarnos prisioneros en el laberinto de las contingencias históricas. En la base de esta visión está la observación según la cual las relaciones que emanan de los sujetos sociales como las familias y las asociaciones familiares deben automatizarse respecto a las determinaciones extrañas y externas a su "carácter originario", si quieren encontrar su emergencia ética y su eficacia operativa.

Si no se coloca en tal sistema de observación, no se puede ver cómo la familia y las asociaciones familiares de primer y segundo nivel puedan organizarse en la sociedad para crear nuevas modalidades de hacer educación. Se precisa que las asociaciones de padres se orienten a producir por sí mismas los bienes relacionales que necesitan. Esto se estimulará enormemente a través de una nueva reflexión sobre el hecho de que toda asociación que se siente "sujeto social", y no solo una agregación de individuos y de intereses, tiene un "motivo fundamental".

Con el término "mito" — que podría también ser denominado "sueño" - entiendo el ideal que hace soñar a aquellos que se adscriben y por el cual están dispuestos a sacrificarse a sí mismos y sus cosas. El mito es darse cuenta de aquella realidad trascendente en la que depositamos nuestras esperanzas y que hace surgir la asociación. El mito alude a esa realidad última por la cual vale la pena dar la propia vida, porque esa es la vida verdadera, la vida más digna de ser vivida, y en ella reside nuestra misma dignidad y felicidad. Naturalmente, no hablo del mito irracional que se construye con los propios 
ídolos, sino del mito verdadero, del que también el cristianismo, que ha desmitificado el mundo antiguo, necesita. Hablo de la verdad del mythos entendido como una historia especial que sabe hablar de las cosas que no se ven, de las realidades que no son traducibles al lenguaje de la verdad racional como la han entendido los modernos. ${ }^{12} \mathrm{El}$ mito del que hablo es "verdadero", es aquel que narra no ya cuentos de hadas o historias inventadas, sino las verdades históricas que son al mismo tiempo una profecía (una anticipación del futuro) que nos pone en relación con las realidades primeras y últimas del destino humano (lo he tratado al final del escrito sobre la laicidad) (Donati, 2008b).

El mito fundamental puede ser más explícito o más implícito, más fuerte o más débil, susceptible de ser manifestado a los otros o menos. Pero en todo caso, debe existir si la asociación no quiere ser simplemente un agregado de individuos. Probablemente la perspectiva aquí indicada conduce a pensar que se necesite refundar, o por lo menos renovar el "mito fundamental" (la visión inspiradora) del hacer una asociación de asociaciones si esta última debe atraer los sentimientos de pertenencia y las identidades de las familias y de las asociaciones singulares, y no ser simplemente un punto de referencia para la comunicación o un agregado de intereses que reducirían con el tiempo las asociaciones familiares (he puesto el ejemplo del Fórum de las Asociaciones Familiares) a un simple lobby.

En el mito fundamental inicial del pacto asociativo del Fórum, y en general de las asociaciones cristianas de padres con finalidades educativas, la idea guía ha sido la de ser y hacer familia en un sentido fuertemente religioso. Este mito se enriquece no solo de redes de transición y de regeneración, sino también de símbolos que tengan que ver con el sentido religioso del asociarse en un proyecto que es mucho más que un contrato: se trata, de hecho, de una alianza que da el sentido de pertenecer a una sociedad que da un valor nuevo y trascendente a la vida civil cotidiana. En definitiva, las asociaciones de padres y familias tienen frente a sí este gran reto.

12 R. Spaemann (1991) afirma: "Oue la Iglesia mantenga un significado decisivo para la cultura europea dependerá entonces del hecho de que sea del todo íntegra, y del hecho de que sea en la doctrina como en el culto y en la ética donde conserve su identidad, o la recupere. Esta presencia posee una doble forma, una de carácter cognitivo y la otra de carácter práctico: el mythos y el ethos. La fuente de la que ambos se sirven es el culto, la oferta de culto, es decir el sacrum commercium, el intercambio sagrado entre el mundo divino y el mundo humano. Por mito entiendo una interpretación de la realidad que difiere fundamentalmente de la interpretación científica. La ciencia presupone siempre el mundo como un todo en el que se deben identificar las reglas uniformes. Cuando la ciencia natural cuenta las his torias - por ejemplo, la evolución del universo materialentonces expone las reconstrucciones hipotéticas basadas sobre determinados datos iniciales y las leyes conocidas de la naturaleza. Al contrario, el mismo es una historia transmitida que precede a cualquier teoría. Se ocupa del mundo en su totalidad como realización singular, de su origen y su destino, de su necesidad de un fundamento suficiente y de las vías para dar cuenta de su constitución. Toda auténtica cultura presupone una cierta narración que explique el mundo en su totalidad. [...] Europa no puede relativizar su mito como si se tratase de un particularismo regional sin con ello renunciar completamente a ello [...] El cor curvatum in se ipsum de un eurocentrismo que se relativiza a sí mis mo acabaría por destruir la cultura europea". 
ISSN $0123-1294$ | Educ.Educ. Vol. 18. No. 2 | Mayo-Agosto de 2015 | pp. 307-329.

Universidad de La Sabana | Facultad de Educación

\section{Referencias}

Archer, M. S. (2006). La conversazione interiore. Come nasce l'agire sociale. Trento: Edizioni Erickson.

Beck, U., Giddens, A. y Lash, S. (1999). Modernizzazione riflessiva: politica, tradizione ed estetica nell'ordine sociale della modernità. Trieste: Asterios.

Bell, D. A. (1995). Residential Community Associations: Community or Disunity? The Responsive Community, 5 (4).

Boffi, P. (ed.) (2001). Famiglie insieme per testimoniare. Panorama sulle aggregazioni di spiritualità familiare in Italia. Siena: Cei-Cisf, Edizioni Cantagalli.

Borzaga, C. y Mittone, L. (1997). The Multi-Stakeholders versus the Nonprofit Organization. University of Trento, Discussion Paper, 7.

Caillé, A. (1998). Il terzo paradigma. Antropologia filosofica del dono. Torino: Bollati Boringhieri.

Chanial, P. (2001). Justice, don et association. La délicate essence de la démocratie. Paris: La Découverte.

Clarke, P. B. (1996). Deep Citizenship. London-Chicago: Pluto Press.

Colombo, M. (ed.) (2005). Riflessività e creatività nelle professioni educative. Una prospettiva internazionale. Milano: Vita e Pensiero.

Colozzi, I. (2009). Sociologia delle istituzioni. Napoli: Liguori.

Comitato Progetto Culturale Cei (ed.) (2009). La sfida educativa. Rapporto-proposta sull'educazione. Roma-Bari: Laterza.

Donati, P. (2006a). L'analisi relazionale: regole, quadro metodologico, esempi. En Donati, P. (ed.). Sociologia. Una introduzione allo studio della società. Padova: Cedam.

Donati, P. (2006b). Disagio giovanile, scuola e capitale sociale. La socializzazione educativa come bene relazionale. En Terenzi,P. Contrasto alla dispersione e promozione del successo formativo (pp. 101-127). Milano: FrancoAngeli.

Donati, P. (2008a). Oltre il multiculturalismo. La ragione relazionale per un mondo comune. Roma-Bari: Laterza.

Donati, P. (2008b). La laicità in una società multiculturale: declinare le differenze con la 'ragione relazionale'. En Donati, P. (ed.). Laicità: la ricerca dell'universale nelle differenze (pp. 141-203). Bologna : il Mulino.

Donati, P. (2009a). La società dell’umano. Genova-Milano: Editrice Marietti 1820.

Donati, P. (2009b). Il ruolo della riflessività nell'agire sociale: quale 'modernizzazione riflessiva'? En Archer, M. S. Riflessività umana e percorsi di vita. Come la soggettività umana influenza la mobilità sociale (pp. 7-49). Trento: Edizioni Erickson.

Donati, P. (2010). Reflexivity after Modernity: From the Viewpoint of Relational Sociology. En Archer, M. S. (ed.). Conversations About Reflexivity (pp. 144-164). London and New York: Routledge. 
Donati, P. y Colozzi, I. (ed.) (1997). Giovani e generazioni. Quando si cresce in una società eticamente neutra. Bologna: il Mulino.

Donati, P.y Colozzi, I. (2006). Capitale sociale delle famiglie e processi di socializzazione. Un confronto fra scuole statali e di privato sociale. Milano: FrancoAngeli.

Donati, P.y Prandini, R. (ed.) (2003). Associare le associazioni familiari: esperienze e prospettive del Forum. Roma: Città Nuova.

Donati, P.y Tronca, L. (2008). Il capitale sociale degli italiani. Le radici familiari, comunitarie e associative del civismo. Milano: FrancoAngeli.

Etzioni, A. (1996). The New Golden Rule: Community and Morality in a Democratic Society. New York: Basic Books.

Godbout, J. (2000). Legami primari, associazioni, Terzo Settore. La prospettiva comunitaria, 2-3, 48-70.

Hirst, P. (1999a). Dallo statalismo al pluralismo. Saggi sulla democrazia associativa. Torino: Bollati Boringhieri.

Hirst, P. (1999b). Associazionalismo: una strategia per l'inclusione. Sociologia e politiche sociali, 2 (3), 173-194.

Johnstad, T. (1997). Co-operatives and Federations. Journal of Co-operative Studies, 30 (89), 48-60.

Lichterman, P. (2002). Oltre la cittadinanza: di che cosa cono capaci le associazioni civili? Sociologia e politiche Sociali, $5,(1), 37-64$.

Luhmann, N. y Schorr, K. E. (1988). Il sistema educativo. Problemi di riflessività. Roma: Armando.

Maclntyre, A. (1988). Dopo la virtù. Saggio di teoria morale. Milano: Feltrinelli.

Osti, G. (2000). Delle contaminazioni del dono. Studi di Sociologia, XXXVIII (2), 189-203.

Panebianco, A. (2009). L'automa e lo spirito. Azioni individuali, istituzioni, imprese collettive. Bologna: il Mulino.

Scola, A. (2007). Una nuova laicità. Temi per una società plurale. Venezia: Marsilio.

Spaemann, R. (1991). La cultura europea e il nichilismo banale, o la unità del mito, culto ed etica. Roma: Conferenza tenuta al Simposio presinodale su 'Cristianesimo e cultura'.

Spaemann, R. (2010). La ragionevolezza della fede in Dio. En Comitato Progetto Culturale Cei (ed.). Dio oggi. Con lui o senza di lui cambia tutto (pp. 57-76). Siena: Cantagalli.

Sturzo, L. (2005) [1947]. La vera vita. Sociologia del soprannaturale. Rubbettino: Soveria Mannelli.

Taylor, Ch. (1994). Il disagio della modernità. Roma-Bari: Laterza.

Taylor, Ch. (2009). Le avventure della ragione dall'Illuminismo in poi. Vita e Pensiero, XCII (6), 10-20.

Viola, F. (2001). Società civile e società politica. En Donati, P. y Colozzi, I. (ed.). Religione, società civile, stato: quale progetto? (pp. 85-102). Bologna: EDB. 
